\title{
INOVASI BATIK MANGROVE BREBESAN SEBAGAI DASAR PENGUATAN BUDAYA LOKAL KABUPATEN BREBES
}

\author{
${ }^{1)}$ M. Dini Adita, ${ }^{2)}$ Mohammad Jusuf Randi \\ 1)Fakultas Sains dan Teknologi, Program StudiAgribisnis, Universitas Muhadi Setiabudi, JI. P. \\ Diponegoro KM 2 Pesantunan Wanasari Brebes, Telp (0283) 6199000, \\ email:muhammaddiniadita@gmail.com \\ ${ }^{2)}$ Fakultas Sains dan Teknologi, Program Studillmu dan Teknologi Pangan, Universitas Muhadi \\ Setiabudi, JI. P. Diponegoro KM 2 Pesantunan Wanasari Brebes, Telp (0283) 6199000, \\ email:randifarmpurwokerto@gmail.com
}

\begin{abstract}
Abstrak
Batik merupakan budaya lokal Indonesia yang patut dilestarikan. Bermula dari identitas batik yang merupakan warisan budaya leluhur, muncul kreativitas dan inovasi dari masyarakat di pesisir pantai Kaliwlingi Desa Pandansari Kabupaten Brebes dalam menumbuhkan industri batik yang berbahan dasar dari tanaman mangrove yang banyak dibudidayakan di daerah tersebut. Industri tersebut mendapat dukungan penuh dari pemerintah di diberi label "Batik Mangrove Brebesan". Tujuan dari penelitian ini adalah untuk 1) meningkatkan koordinasi antara perajin batik mangrove brebesan dalam menguatkan sentra batik mangrove brebesan untuk mendukung peningkatan Objek Wisata Dewi Mangrove Sari di Kabupaten Brebes dan 2) mengembangkan Objek Wisata Dewi Mangrove Sari di Kabupaten Brebes yang berbasis seni dan budaya lokal. Penelitian dilakukan dengan menggunakan metode Discovery Learning and Development Model untuk merumuskan model pengembangan batik mangrove brebesan. Hasil penelitian menunjukkan bahwa pengembangan batik mangrove brebesan sangat erat kaitannya dengan pertumbuhan industri lokal dan kreatif serta mendorong timbulnya industri-industri sejenis di kawasan Objek Wisata Dewi Mangrove Sari di Kabupaten Brebes. Sentra industri batik mangrove brebesan akan menjadi daya tarik wisata yang tentunya akan meningkatkan minat wisatawan dalam berkunjung.
\end{abstract}

Kata kunci: batik mangrove brebesan, inovasi, penguatan budaya

\begin{abstract}
Batik is a local Indonesian culture that deserves to be preserved. Starting from the identity of batik that is the ancestral cultural heritage, emerging creativity and innovation from the coastal community Kaliwlingi Village Pandansari Brebes Regency in growing the batik industry based on mangrove plants that Many cultivated in the area. The industry received full support from the government in labelled "Batik Mangrove Brebesan". The purpose of this research is to 1) improve the coordination between the batik craftsmen of mangrove Brebesan in strengthening the center of mangrove Batik Brebesan to support the enhancement of the tourism object of Dewi Mangrove Sari in Brebes and 2) develop The object of Dewi Mangrove Sari in Brebes based on local art and culture. The research was conducted using a method of Discovery Learning and Development Model to complicit the development model of batik mangrove Brebesan. The results showed that the development of batik mangrove Brebesan is very closely related to the growth of local and creative industries and encourages the emergence of similar industries in the area of Dewi Mangrove Sari Tourism object in Brebes Regency. Industrial Center Batik Mangrove Brebesan will be a tourist attraction that will certainly increase the interest of tourists in a visit.
\end{abstract}

Keywords: batik mangrove Brebesan, innovation, strenghthening the culture 


\section{PENDAHULUAN}

Batik merupakan salah satu budaya lokal Indonesia yang patut untuk dilestarikan. Industri kerajinan batik telah berkembang di hampir di seluruh penjuru wilayah Negara Indonesia. Tiap-tiap wilayah mempunyai motif batik sendiri yang mencirikan kebudayaan masing-masing wilayah. Kesadaran masyarakat dalam menggunakan batik telah menjadi bagian dalam pembentukan ciri-ciri bangsa Indonesia. Industri batik yang ada di Indonesia merupakan salah satu pendorong kemajuan perekonomian nasional yang dapat menyerap banyak tenaga kerja.

Batik merupakan hasil kreasi budaya masyarakat yang memiliki keistimewaan dalam penciptaannya. Seni membatik memiliki filosofi yang tinggi dan mengandung tiga unsur yang berkaitan yaitu motif, fungsi, dan filosofi. Ada dua hal yang terkait dengan batik yaitu batik dalam pengertian proses produksinya dan batik sebagai kain yang memiliki motif yang spesifik (Suliyati \& Yuliati, 2019).

Terdapat berbagai jenis dan model batik yang menunjukkan ciri dari masing-masing daerah diantaranya adalah Daerah Istimewa Yogyakarta, Surakarta, Pekalongan, Cirebon, Madura, Tuban, dan Banyuwangi (Poerwanto \& Sukirno, 2012). Masing-masing daerah tersebut mempunyai pasar dan kekuatan masing-masing.

Salah satu produk batik yang sedang berkembang di Indonesia adalah Batik Mangrove Brebesan. Batik Mangrove Brebesan merupakan jenis batik yang diproduksi oleh masyarakat di kawasan pesisir pantai Desa Kaliwlingi Kabupaten Brebes. Tinta Batik Mangrove Brebesan terbuat dari daun mangrove yang sudah kering dan tidak terpakai. Perajin Batik Mangrove Brebesan memiliki peluang yang maih sangat terbuka untuk terus mengembangkan inovasi-inovasi Batik Mangrove Brebesan dengan motif yang lebih variatif sehingga dapat bersaing di tingkat nasional maupun internasional.

Variasi dalam pengembangan batik mangrove dapat dilihat dari variasi motif yang dihasilkan mulai dari daun, bunga, untaian buah, sampai dengan makhluk hidup yang ada di sekitarnya seperti ikan, udang, kepiting, dan karang (Kurniawati \& Yulistiana, 2015). Tantangan ke depan adalah bagaimana para perajin dapat mengantisipasi dinamika pasar supaya Batik Mangrove Brebesan dapat terus bertahan di pasar nasional dan menjadi salah satu basis penguatan ekonomi kreatif di Indonesia.

Eksistensi batik sebagai budaya bangsa telah mengalami pasang surut dapam penemuan identital budayanya. Kesadaran akan identitas budaya batik dimulai dari unexamied cultural identity, cultural identity search, sampai cultural identity achievement. Saat ini, Indonesia telah mencapai masa cultural identity achievement seiring dengan pengukuhan intangible culture dari Indonesia oleh UNESCO (Iskandar dan Eny, 2017). Pencapaian ini merupakan tantangan bagi masyarakat Indonesia dalam mempertahankan nilai-nilai budaya bangsa melalui karya seni batik yang merupakan identitas, penjelasan strata sosial, kebudayaan, spiritualitas, teknologi, dan perjalanan suatu peradaban yang menjadi identitas bangsa Indonesia (Iskandar dan Eny, 2017).

Tujuan dari penelitian ini adalah untuk 1) meningkatkan koordinasi antara perajin batik mangrove brebesan dalam menguatkan sentra batik mangrove brebesan untuk mendukung peningkatan Objek Wisata Dewi Mangrove Sari di Kabupaten Brebes dan 2) mengembangkan Objek Wisata Dewi Mangrove Sari di Kabupaten Brebes yang berbasis seni dan budaya lokal.

\section{BAHAN DAN METODE}

\subsection{Metode Pengambilan Data}

Penelitian dilakukan di Objek Wisata Dewi Mangrove Sari Desa Kaliwlingi Kabupaten Brebes dan merupakan penelitian lapangan yang melibatkan pembelajaran tentang pemahaman dan penggambaran suatu kelompok yang ada di suatu tempat. Pengambilan data dilakukan dengan menggunakan metode observasi dan wawancara. Observasi dilakukan dengan mengamati proses pembatikan mulai dari pengambilan bahan baku sampai dengan pemasaran. Pengambilan sampel dilakukan secara purposive sampling dengan sampel yang homogen. Pengambilan sampel dilakukan dengan menggunakan metode quota sampling dengan jumlah sampel sebanyak 35 orang. Sampel yang digunakan dalam penelitian ini adalah pelopor Batik 
Mangrove Brebesan, para perajin, dan dinas terkait.

\subsection{Analisis Data}

Penelitian dilakukan dengan metode deskriptif kualitatif dengan mengindikasikan potensi Batik Mangrove Brebesan yang mencakup proses produksi, motif, pengembangan usaha, pesaing, dan pemasaran. Analisis data dengan pendekatan restrospektif dan prospektif. Pendekatan retrospektif dengan mengevaluasi kondisi internal dalam industri Batik Mangrove Brebesan dan pendekatan prospektif dengan meramalkan dan mengantisipasi kondisi eksternal diantaranya adalah peluang dan ancaman pengembangan Batik Mangrove Brebesan.

Focus Group Discussion (FGD) telah dilakukan untuk merumuskan model inovasi pengembangan Batik Mangrove Brebesan. FGD melibatkan beberapa komponen masyarakat yang terdiri dari pelopor industri Batik Mangrove Brebesan, para perajin, dan dinas terkait dalam hal ini adalah Dinas Kebudayaan dan Pariwisata serta Dinas Perindustrian dan Tenaga Kerja Kabupaten Brebes.Roadmap penelitian ini disajikan dalam lampiran.

\section{HASIL DAN PEMBAHASAN}

Batik mangrove brebesan merupakan salah satu jenis batik pesisiran karena lokasi industri berada di pesisir pantai pulau Jawa. Beberapa daerah pesisir yang juga memproduksi batik diantaranya adalah Pekalongan, Semarang, Tuban, Lasem, dan Juwana Pati. Batik pesisiran bersifat Vorstenlanden yang berarti tidak mencirikan suatu daerah atau kerajaan. Batik pesisiran lebih bersifat naturalistik dan menunjukkan kebudayaan dengan motif sesuai dengan daerah masing-masing (Poerwanto \& Sukirno, 2012). Saat ini, Kabupaten Brebes pun mulai mencoba memperkenalkan batik yang berlokasi di pesisiran Pantai Utara Pulau Jawa.

Satu dari sekian banyak lokasi wisata yang ada di Kabupaten Brebes adalah Dewi Mangrove Sari atau Desa Wisata Mangrove Sari yang ada di Desa Kaliwlingi Kabupaten Brebes. Pemerintah saat ini sedang gencar mempromosikan Mangrove Sari sebagai destinasi wisata baru di Kabupaten Brebes dengan produk yang menjadi ciri khas adalah batik mangrove brebesan. Batik mangrove brebesan merupakan salah satu inovasi yang menggunakan bahan baku tinta dari mangrove yang sudah mati. Hal tersebut merupakan kearifan lokal yang sedang dikembangkan di Kabupaten Brebes. Kehadiran batik mangrove akan meningkatkan khasanah batik di Kabupaten Brebes. Pengembangan batik mangrove brebes tentunya masih membutuhkan dari pihak terkait utamanya dalam sektor pemasaran (Purnamasari, 2016). Perlu program yang cukup kreatif salah satunya dengan pengemasan paket wisata yang merupakan strategi untuk menarik pengunjung.

Kreativitas masyarakat Desa Kaliwlingi dalam mengembangkan batik mangrove brebesan telah bekembang pesat dari industri rumahan menjadi industri yang telah berskala nasional. $\mathrm{Di}$ Desa Kaliwlingi telah dibuat suatu kelompok perajin batik mangrove brebesan yang telah mempunyai lokasi sentra sehingga memudahkan pengunjung yang akan melihat dan mempelajari seluk beluk batik mangrove brebesan. Pengembangan batik mangrove brebesan dapat dilakukan dengan mengembangkan motif yang sudah ada saat ini. Pengembangan kain batik dengan transformasi motif kain batik dapat dilakukan dengan stilasi motif ethno modern dengan menggabungkan motif tradisional dan motif modern menjadi suatu motif baru dengan tetap mempertahankan makna dengan teknik transformasi yang suda ada (Wening et al., 2013).

\subsection{Focus Group Discussion}

Menurut Menteri Perdagangan Republik Indonesia, inovasi dalam industri kreatif merupakan aktivitas dalam mengekploitasi dan mengeksplorasi ide baru sedangkan kreativitas merupakan kegiatan dalam implementasi ide baru ke dalam suatu bentuk inovasi. Desain membantu mentransformasikan teknologi baru menjadi produk yang berdaya guna serta berdaya saing yang mampu menjadi penghubung bagi masyarakat (Poerwanto \& Sukirno, 2012).

Stakeholder utama dalam pengelolaan suatu usaha adalah masyarakat. Kearifan lokal menjadi satu prioritas yang harus dijaga dalam pengembangan batik mangrove brebesan karena kearifan lokal dianggap 
ramah lingkungan dan dapat menyerap lebih banyak tenaga kerja lokal (Ghazali, 2015).

Proses penciptaan nilai industri batik terdiri dari variabel kreasi, produksi, distribusi, dan komersialisasi mulai dari perencanaan bahan baku sampai dengan jaringan pemasaran batik mangrove brebesan. Partisipasi aktif dari seluruh stakeholder akan menghasilkan suatu model mapping value chain dari seluruh komponen yang terkait (Khoiroh, 2017).

Faktor utama terciptanya industri kreatif yang berdaya saing telah dijelaskan dalam konsep Triple Helix yang dikeluarkan oleh Departemen Perdagangan Republik Indonesia yang merupakan sebuah konsep pembangunan kebijakan berbasis inovasi. Triple Helix menggambarkan sinergi yang baik antara akademisi, pelaku bisnis, dan pemerintah. Harapannya adalah terciptanya pembangunan berkelanjutan yang didukung oleh ilmu pengetahuan dan terjadi perputaran maupun transfer pengetahuan yang berujung pada terciptanya inovasi. Peran masingmasing komponen dalam Triple Helix adalah akademisi yang berperan dalam penciptaan (novelty) gagasan yang memiliki daya saing di pasar serta dapat membentuk kreativitas baru, pelaku bisnis dalam hal ini adalah perajin batik mangrove brebesan yang dapat mentransformasikan kreativitas dari akademisi menjadi sebuah produk yang punya nilai ekonomi tinggi, dan pemerintah sebagai pihak yang mengeluarkan kebijakan-kebijakan yang dapat mendukung pengembangan batik mangrove brebesan.

Dalam pelaksanaan Focus Group Discussion tentunya melibatkan tiga komponen yaitu akademisi, pelaku bisnis, dan pemerintah Kabupaten Brebes. Analisis restrospektif yang telah dilakukan dalam Focus Group Discussion menghasilkan suatu temuan bahwa secara umum produksi batik mangrove brebesan mengalami peningkatan yang signifikan setiap tahun. Pemasaran batik mangrove brebesan telah mencapai skala nasional dan telah beberapa kali mengikuti festival-festival batik di tingkat nasional. Pencapaian yang baik tersebut tercipta karena meningkatnya kesadaran dari para perajin batik dalam meningkatkan kualitas dari batik mangrove brebesan yang mereka produksi. Namun, para perajin masih terkendala dengan kuantitas produksi batik mangrove brebesan. Saat ini, perajin hanya memproduksi batik sesuai dengan jumlah pesanan yang diterima dan hanya menyisakan sedikit untuk keperluan pameran. Pemasaran batik mangrove brebesan belum intensif untuk mendukung pengembangan desa wisata mangrove sari dengan ciri khas batik yang dimiliki. Perlu program peningkatan kesadaran berwirausaha bagi masyarakat desa Kaliwlingi untuk turut serta dalam pengembangan batik mangrove brebesan.

Kemudian, analisis prospektif menunjukkan bahwa industri batik mangrove brebesan dapat menciptakan lapangan pekerjaan bagi masyarakat sekitar sehingga imbasnya dapat meningkatkan perekonomian nasional. Semakin meningkatnya jumlah perajin batik mangrove brebesan tentunya akan meningkat pula persaingan antar pelaku usaha. Peran pemerintah sangat diperlukan untuk tetap menciptakan iklim usaha yang kondusif dan dapat mengakomodasi seluruh kepentingan perajin batik mangrove brebesan. Pemerintah Kabupaten Brebes dapat pula membuat kebijakan dan peraturan untuk pembetukan tim pelaksana penentuan Objek Wisata Dewi Mangrove Sari sebagai daerah tujuan wisata prioritas. City Branding Kabupaten Brebes dengan kawasan prioritas Objek Wisata Dewi Mangrove Sari dengan ciri khas batik mangrove sari sebagai branding akan lebih mendatangkan pengunjung dalam menciptakan brand yang lebih emosional dan membangun citra Kabupaten Brebes (Wibowo, 2018).

\subsection{Rekomendasi Pengembangan Batik Mangrove Brebesan}

Untuk merumuskan strategi-strategi pengembangan batik mangrove brebesan, dilakukan analisis Discovery Learning and Development Model. Analisis Discovery Learning and Development Model menghasilkan suatu konsep model pengembangan batik mangrove brebesan yang sesuai dengan prinsip pembangunan berkelanjutan dengan tetap mempertahankan kearifan lokal dan penciptaan batik yang ramah lingkungan dengan penggunaan bahan kimiawi yang minimal. Perlu penciptaan kebijakan-kebijakan strategis yang terkoordinasi untuk melakukan pembinaan model inovasi batik mangrove brebesan yang berbasis pada kearifan lokal. 
Agrisaintifika

Jurnal Ilmu-Ilmu Pertanian

Vol. 4, No. 1, 2020

Adita \& Randi. 2020

Perlu kolaborasi yang efektif antar berbagai komponen dalam menciptakan model pembinaan inovasi produk batik mangrove brebesan yang dapat mendukung pengembangan ekonomi kreatif. Setiap komponen memiliki peran dan tantangan masing-masing untuk menjadi model pengembangan industri batik mangrove brebesan. Strategi diversifikasi produk dan inovasi peralatan produksi batik dapat dilakukan sebagai upaya peningkatan jumlah produksi, inovasi peralatan dan inovasi sarana membatik merupakan upaya dalam peningkatan kualitas dan kuatitas produk batik (Hermawati et al., 2018).

Model pembinaan batik mangrove brebesan yang dilakukan adalah dengan mengadopsi model pembinaan batik pesisiran yang ada di Kota Pekalongan disajikan dalam lampiran.

\section{KESIMPULAN}

Kesimpulan dalam penelitian ini adalah bahwa pengembangan batik mangrove brebesan sangat erat kaitannya dengan pertumbuhan industri lokal dan kreatif serta mendorong timbulnya industri-industri sejenis di kawasan Objek Wisata Dewi Mangrove Sari di Kabupaten Brebes. Sentra industri batik mangrove brebesan akan menjadi daya tarik wisata yang tentunya akan meningkatkan minat wisatawan dalam berkunjung.

Analisis restrospektif menghasilkan suatu temuan bahwa secara umum produksi batik mangrove brebesan mengalami peningkatan yang signifikan setiap tahun. Pemasaran batik mangrove brebesan telah mencapai skala nasional dan telah beberapa kali mengikuti festival-festival batik di tingkat nasional. Pencapaian yang baik tersebut tercipta karena meningkatnya kesadaran dari para perajin batik dalam meningkatkan kualitas dari batik mangrove brebesan yang mereka produksi. Kemudian, analisis prospektif menunjukkan bahwa industri batik mangrove brebesan dapat menciptakan lapangan pekerjaan bagi masyarakat sekitar sehingga imbasnya dapat meningkatkan perekonomian nasional. Semakin meningkatnya jumlah perajin batik mangrove brebesan tentunya akan meningkat pula persaingan antar pelaku usaha. Peran pemerintah sangat diperlukan untuk tetap menciptakan iklim usaha yang kondusif dan dapat mengakomodasi seluruh kepentingan perajin batik mangrove brebesan.

\section{DAFTAR PUSTAKA}

Ghazali, I. (2015). Pemanfaatan Mangrove Berbasis Kearifan Lokal di Pantai Timur Surabaya.Institut Pertanian Bogor, Bogor.

Hermawati, A., Isma, Y. El, \& Mas, N. (2018). Strategi Bersaing: Batik Malangan Konvensional Melalui Diversifikasi Produk Batik Kombinasi Pada Ukm Kelurahan Merjosari Malang. Jurnal IImiah Bisnis Dan Ekonomi Asia, 11(1), 11-23.

Khoiroh, S. M. (2017). Optimalisasi Pengembangan Kampung Industri Batik Tulis Daerah berdasarkan Mapping Value Chain. Seminar Dan Konferensi Nasional IDEC, 125-135.

Kurniawati, E., \& Yulistiana. (2015). Batik Mangrove Rungkut Surabaya. E-Journal, 04(1), 37-45.

Poerwanto, \& Sukirno, Z. L. (2012). Inovasi Produk dan Motif Seni Batik Pesisiran sebagai Basis Pengembangan Industri Kreatif dan Kampung Wisata Minat Khusus. Jurnal Al Azhar Indonesia Seri Pranata Sosial, 1(4), 217-229.

Purnamasari,M (2016). Analisis Potensi dan Preferensi Konsumen Batik Bakau ( Studi Kasus Di Zie Batik Semarang ).Universitas Negeri Semarang, Semarang.

Iskandar \& Eny K (2017). Batik sebagai Identitas Kultural Bangsa Indonesia di Era Globalisasi. GEMA XXX(52), 2456 2472.

Suliyati, T., \& Yuliati, D. (2019). Pengembangan Motif Batik Semarang untuk Penguatan Identitas Budaya Semarang. Jurnal Sejarah Citra Lekha, 4(1), 61-73.

Wening, S., Eny,Z, \& Sri E (2013). Pengembangan Produk dan Strategi Pemasaran Busana Batik Bantulan dengan Stilasi Motif Ethno Modern. Jurnal Penelitian Humaniora, 18(1), 70 81.

Wibowo, T. O. (2018). Strategi 
Adita \& Randi. 2020

Pengembangan Daya Tarik Kota Lasem Sebagai Kota Batik-Kopi. Jurnal

\section{Lampiran}

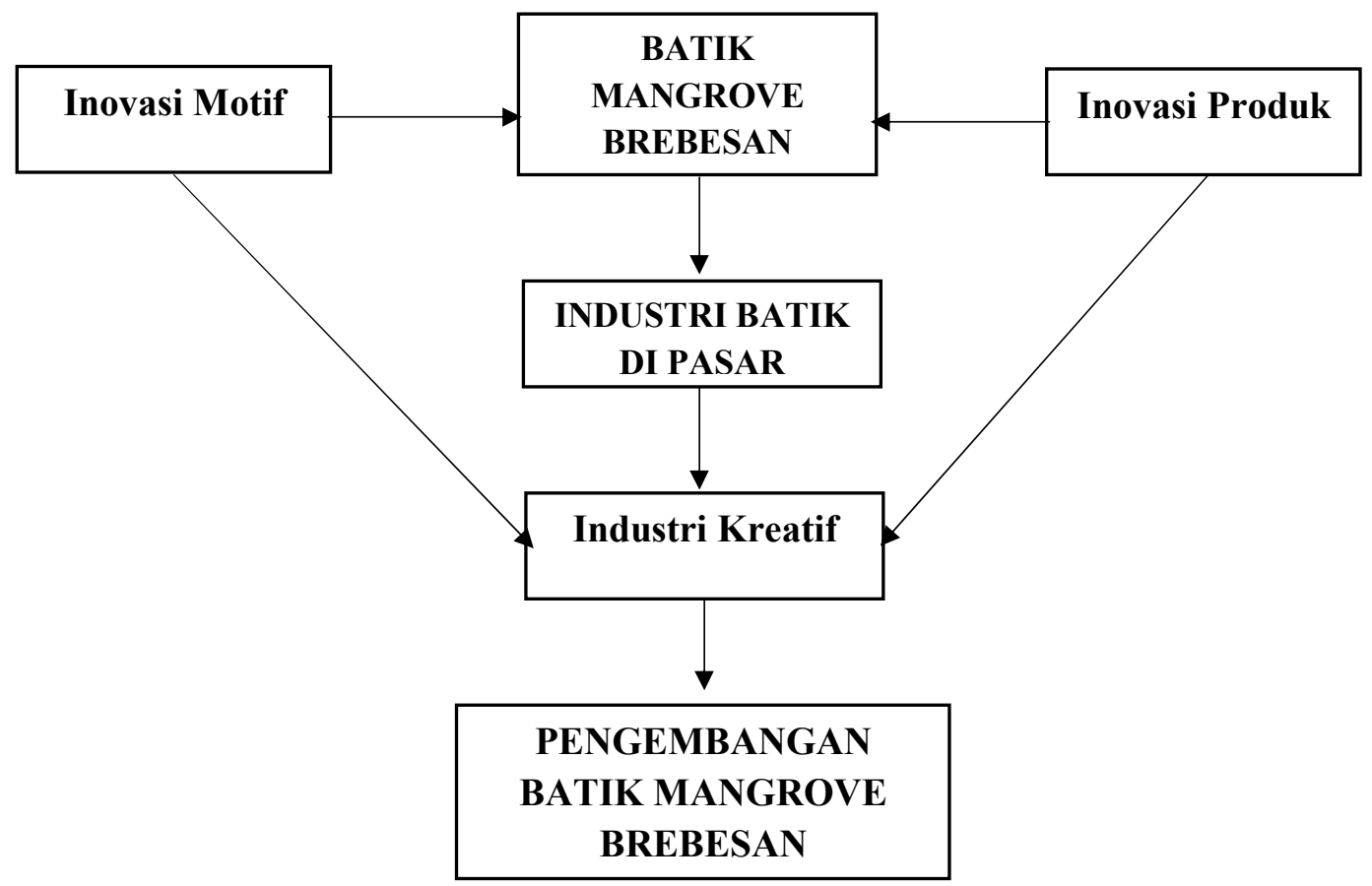

Gambar 1. Roadmap Penelitian

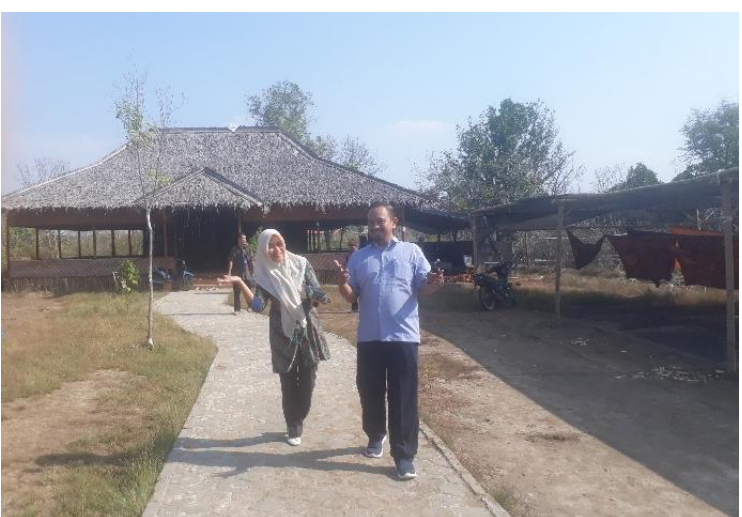

Gambar 2. Sentra Batik Mangrove Brebesan

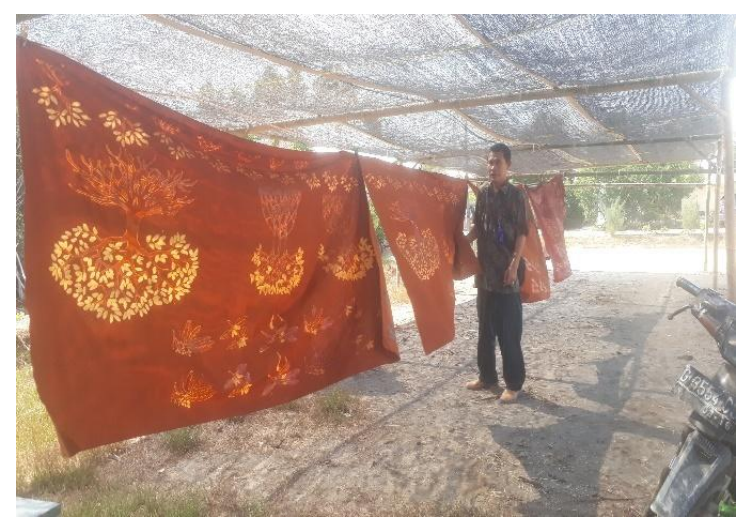

Gambar 3. Motif Batik 


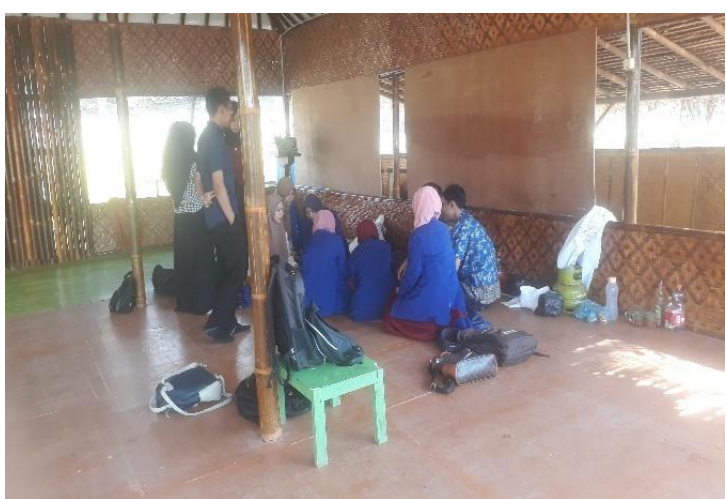

Gambar 4. Kegiatan Pengunjung

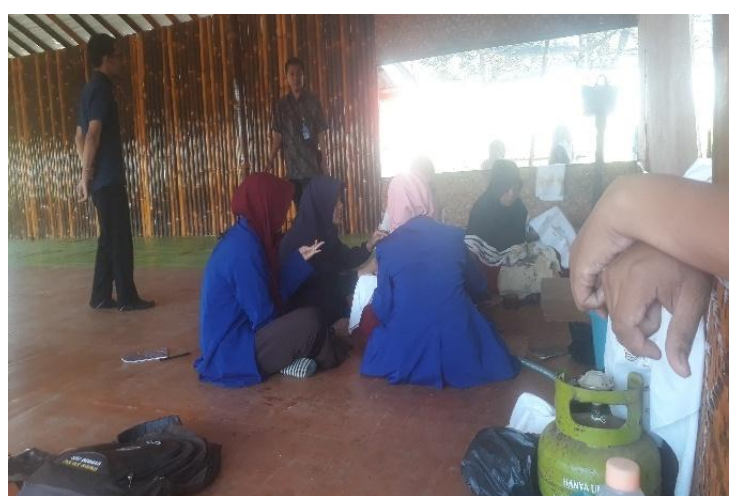

Gambar 5. Motif Batik

Tabel 1. Model Pembinaan Batik Mangrove Brebesan dengan Kolaborasi Antar Komponen

\begin{tabular}{|c|c|c|c|c|}
\hline Komponen & Masyarakat & Teknologi & Sumber Daya & Lembaga Keuangan \\
\hline Akademisi & $\begin{array}{l}\text { Memberikan } \\
\text { transfer } \\
\text { knowledge agar } \\
\text { masyarakat } \\
\text { memiliki } \\
\text { kreativitas dalam } \\
\text { penciptaan batik } \\
\text { mangrove } \\
\text { brebesan yang } \\
\text { lebih inovatif }\end{array}$ & $\begin{array}{l}\text { Menciptakan } \\
\text { teknologi baru } \\
\text { dalam } \\
\text { pengembangan } \\
\text { batik supaya } \\
\text { hasil lebih } \\
\text { efektif dan } \\
\text { efisien }\end{array}$ & $\begin{array}{l}\text { Memberikan } \\
\text { informasi } \\
\text { bagaimana } \\
\text { mengoptimalkan } \\
\text { sumber daya } \\
\text { yang dimiliki oleh } \\
\text { perajin untuk } \\
\text { menghasilkan } \\
\text { keuntungan yang } \\
\text { optimal }\end{array}$ & $\begin{array}{l}\text { Membantu dalam } \\
\text { koordinasi } \\
\text { penyediaan bantuan } \\
\text { modal untuk } \\
\text { mendorong } \\
\text { tumbuhnya industri } \\
\text { batik mangrove } \\
\text { brebesan yang baru }\end{array}$ \\
\hline $\begin{array}{c}\text { Perajin } \\
\text { Batik } \\
\text { Mangrove } \\
\text { Brebesan }\end{array}$ & $\begin{array}{l}\text { Menyebarluaskan } \\
\text { inovasi batik } \\
\text { mangrove } \\
\text { brebesan yang } \\
\text { diproduksi } \\
\text { supaya dapat } \\
\text { menggugah } \\
\text { kesadaran } \\
\text { masyarakat } \\
\text { dalam } \\
\text { keikutsertaan } \\
\text { pengembangan } \\
\text { batik mangrove } \\
\text { brebesan }\end{array}$ & $\begin{array}{l}\text { Perajin aktif } \\
\text { mencari } \\
\text { informasi } \\
\text { mengenai } \\
\text { teknologi- } \\
\text { teknologi baru } \\
\text { yang dapat } \\
\text { membantu } \\
\text { dalam } \\
\text { pengembangan } \\
\text { batik mangrove } \\
\text { brebesan }\end{array}$ & $\begin{array}{l}\text { Perajin harus } \\
\text { dapat } \\
\text { memanfaatkan } \\
\text { sumber daya } \\
\text { yang dimiliki } \\
\text { dalam rangka } \\
\text { pengembangan } \\
\text { batik mangrove } \\
\text { brebesan }\end{array}$ & $\begin{array}{l}\text { Perajin harus memiliki } \\
\text { gagasan yang inovatif } \\
\text { supaya lembaga } \\
\text { keuangan memiliki } \\
\text { alasan yang logis } \\
\text { dalam pencairan } \\
\text { bantuan modal bagi } \\
\text { para perajin batik }\end{array}$ \\
\hline Pemerintah & $\begin{array}{l}\text { Ikut serta secara } \\
\text { rutin melakukan } \\
\text { kegiatan } \\
\text { pemberdayaan } \\
\text { masyarakat } \\
\text { dalam rangka } \\
\text { pemunculan } \\
\text { sosok-sosok } \\
\text { wirausahawan } \\
\text { baru yang dapat } \\
\text { mengembangkan } \\
\text { batik mangrove } \\
\text { brebesan }\end{array}$ & $\begin{array}{l}\text { Memberikan } \\
\text { bantuan } \\
\text { teknologi baru } \\
\text { untuk } \\
\text { pengembangan } \\
\text { batik mangrove } \\
\text { brebesan }\end{array}$ & $\begin{array}{l}\text { Menjamin } \\
\text { kecukupan } \\
\text { sumber daya } \\
\text { yang dimiliki oleh } \\
\text { perajin batik } \\
\text { mangrove } \\
\text { brebesan dan } \\
\text { memberikan } \\
\text { solusi bagi perajin } \\
\text { yang mengalami } \\
\text { kesulitan dalam } \\
\text { usahanya }\end{array}$ & $\begin{array}{l}\text { Pemerintah } \\
\text { membantu } \\
\text { memfasilitasi dalam } \\
\text { penyediaan bantuan } \\
\text { modal bagi perajin } \\
\text { batik mangrove } \\
\text { brebesan yang } \\
\text { mengalami kesulitan } \\
\text { modal }\end{array}$ \\
\hline
\end{tabular}

